\title{
PEMETAAN ZONASI INTRUSI AIR LAUT DI KOTA LANGSA
}

\author{
Abdurrachman ${ }^{1}$, Rosmaiti $^{2}$, Iswahyudi ${ }^{2}$ \\ ${ }^{1}$ Dosen Program Studi Agribisnis, Fakultas Pertanian Universitas Samudra \\ ${ }^{2}$ Dosen Program Studi Agroteknologi, Fakultas Pertanian Universitas Samudra \\ e-mail: maman.rc87@gmail.com
}

\begin{abstract}
ABSTRAK
Pengelolaan sumber daya air tanah di Kota Langsa sangat diperlukan terutama dalam perencanaan, pendayagunaan dan konservasi. Guna membantu pengelolaan tersebut, dibutuhkan informasi tentang kondisi lingkungan air tanah. Tujuan penelitian untuk untuk memetakan zonasi intrusi air laut di Kota Langsa berdasarkan parameter Daya Hantar Listrik (DHL) dan Padatan Terlarut Total (TDS) dengan klasifikasi PAHIAA (1986). Hasil penelitian menunjukkan zonasi intrusi air laut di Kota Langsa berdasarkan pengukuran nilai TDS dan DHL berada pada klasifikasi tawar sampai payau. Zona payau dijumpai di wilayah yang jaraknya dekat dengan garis pantai dengan tutupan lahan dominan hutan mangrove, tambak dan pemukiman.
\end{abstract}

Kata kunci : Air tanah, TDS, DHL, zonasi.

\section{PENDAHULUAN}

Kota Langsa sebagai pusat jasa dan perdagangan di pesisir timur Propinsi Aceh pada saat ini menghadapi banyak tantangan seiring dengan pertumbuhan jumlah penduduk yang semakin meningkat. Hal ini ditandai oleh pertumbuhan jasa dan perdagangan yang menunjukkan arah yang positif. Salah satu kebutuhan pokok yang sangat penting untuk menunjang pertumbuhan jasa dan perdagangan di Kota Langsa adalah air tanah.

Air tanah merupakan sumberdaya yang sangat penting yang digunakan untuk keperluan sehari-hari. Masyarakat di Kota Langsa sebagian besar menggunakan sumur bor dengan akuifer dalam dan sumur gali sebagai sumber air bersih. Eksploitasi air tanah di Kota Langsa dalam memenuhi kebutuhan penduduk pada jangka waktu yang panjang dapat menyebabkan terganggunya sistem hidrologi yang dapat menyebabkan berkurangnya kuantitas dan kualitas air tanah.

Intrusi air laut merupakan salah satu penyebab menurunnya kualitas air tanah. Intrusi air laut merupakan fenomena alam yang memungkinkan masuknya air asin ke akuifer (Irham dkk, 2006). Menurut Pla, dkk (2014) Penggunaan air tanah yang berlebihan disepanjang garis pantai dapat mempercepat terjadinya intrusi air laut yang pada akhirnya dapat menyebabkan salinisasi sumber air tanah.

Intrusi air laut menyebabkan air tanah menjadi terkontaminasi dari tawar, payau, hingga asin (Dogan dan Fares, 2008). Oleh sebab itu, perlu diidentifikasi keberadaan air tanah agar tidak terjadi perluasan 
intrusi air laut. Penurunan kualitas air tanah dapat dilihat dari tingkat kegaraman air tanah berdasarkan kadar ion klorida yang ditunjukkan dengan nilai Padatan Terlarut Total (TDS) dan nilai Daya Hantar Listrik (DHL) air tanah (Effendi, 2003).

Pengelolaan sumber daya air tanah di Kota Langsa sangat diperlukan terutama dalam perencanaan, pendayagunaan dan konservasi. Guna membantu pengelolaan tersebut, dibutuhkan informasi yang cukup rinci tentang kondisi lingkungan air tanah. Adapun tujuan dari penelitian ini adalah untuk memetakan zonasi intrusi air laut di Kota Langsa berdasarkan parameter Daya Hantar Listrik (DHL) dan Padatan Terlarut Total (TDS) dengan klasifikasi PAHIAA (1986).

\section{METODE PENELITIAN} Waktu dan Lokasi Penelitian Penelitian ini telah dilaksanakan di Kota Langsa Provinsi Aceh, selama 4 bulan (bulan Juni sampai dengan bulan September 2018). Penentuan lokasi penelitian dilakukan secara "purposive". Peta lokasi penelitian disajikan pada Gambar 1.

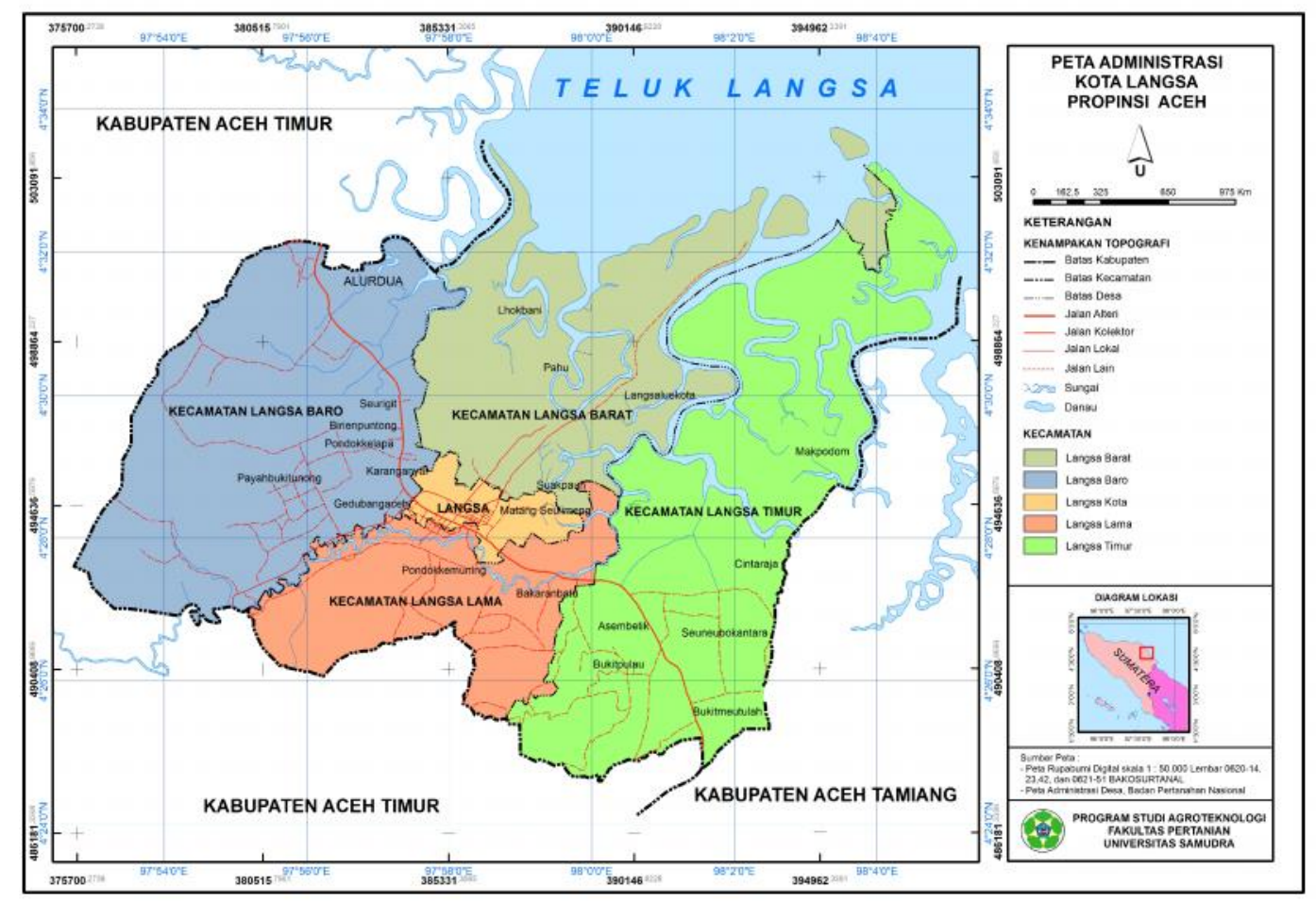

Gambar 1. Peta lokasi penelitian

\section{Bahan dan Alat}

Bahan yang digunakan antara lain: sampel air tanah sumur warga di Kota Langsa, Peta Dasar (Peta Rupa Bumi Indonesia/tematik Kota Langsa Skala 1:50.000; Peta Penggunaan
Lahan, Peta Topografi, dan Peta Geologi Kota Langsa).

Alat-alat yang digunakan antara lain: seperangkat komputer yang dilengkapi perangkat lunak Sistem Informasi Geografis (Arc 
GIS) dan Microsoft office, TDS Meter Milwaukee CD 600, Conductivity Meter Milwaukee CD 601 dan peralatan survey lapangan

\section{Tahapan Penelitian}

Tahap Evaluasi dan Koordinasi

Jumlah titik pengambilan sampel air sumur dalam penelitian sebanyak 15 titik sampel yang menyebar di 5 wilayah kecamatan yang terdapat di Kota Langsa. Masing-masing titik sampel tersebut mewakili desa yang berada dekat dengan wilayah pantai, wilayah pertengahan dan wilayah dataran tinggi. Penentuan jumlah titik dan letak desa yang diukur nilai TDS dan DHLnya berdasarkan peta (form isian survei, alat tulis menulis, Global Positioning System (GPS) Garmin, kamera, dan sarana transportasi).

administrasi yang telah dibuat. Titik pengambilan sampel air tanah disajikan pada Gambar 2.

Pengukuran nilai TDS dan DHL, dilakukan melalui penentuan titik pengambilan sampel menggunakan GPS yang kemudian dicatat. Air tanah yang diambil diukur menggunakan TDS Meter Milwaukee CD 600, Conductivity Meter Milwaukee CD 601 (dilakukan selama tiga kali pengulangan untuk mendapatkan nilai rataan DHL sumur tersebut).

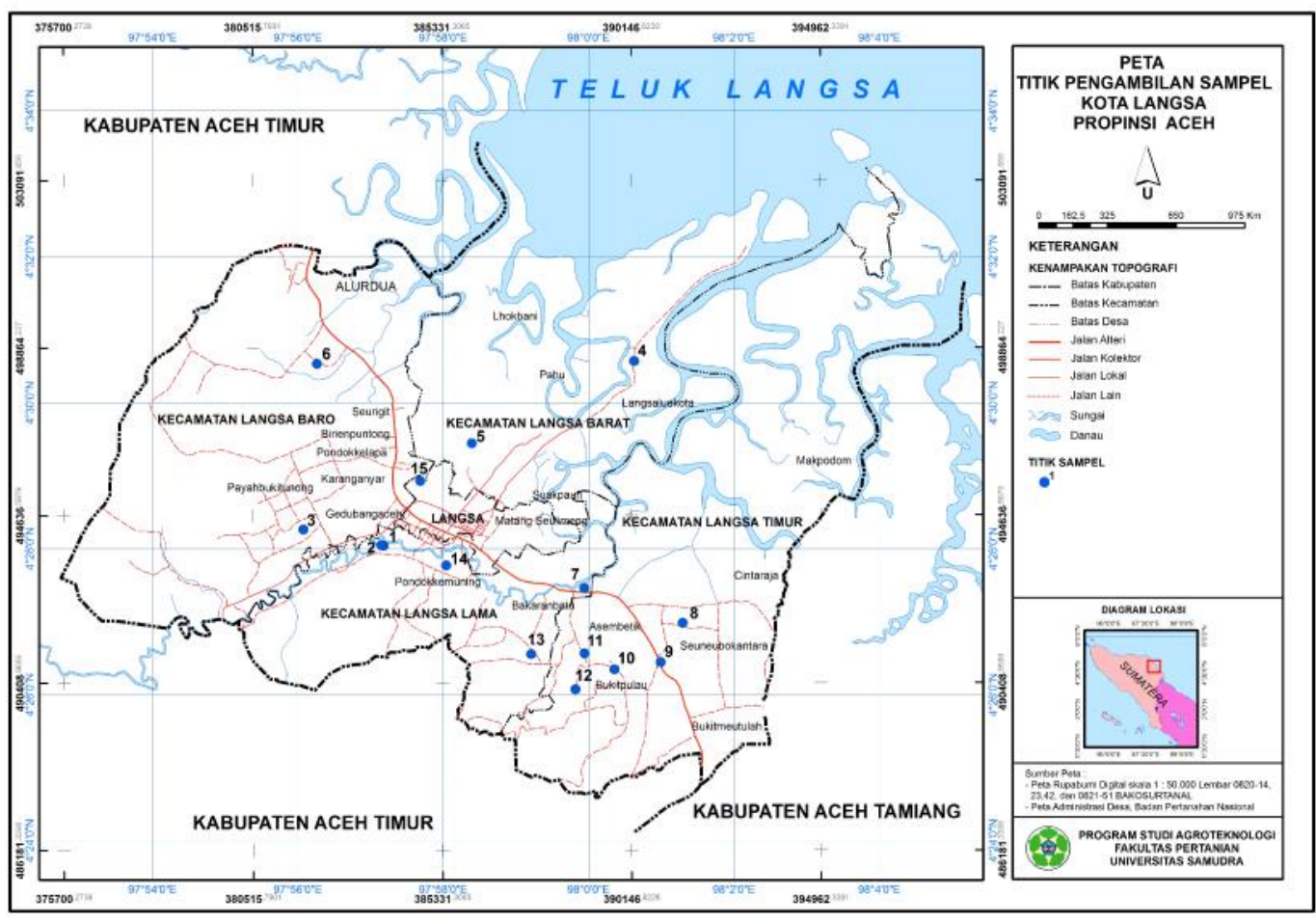

Gambar 2. Titik pengambilan sampel air tanah

Metode Analisis Data

Analisis nilai Daya Hantar Listrik dan Total Dissolved Solid
Mengacu pada Keputusan Panitia Ad Hoc Intrusi Air Asin (PAHIAA) (1986). Analisis data yang digunakan berdasarkan nilai 
DHL dan TDS. Gambaran umum zona batasan intrusi terlihat melalui

\section{HASIL DAN PEMBAHASAN}

Intrusi air laut di Kota Langsa dipengaruhi oleh letaknya dekat dengan pantai, perubahan pola penggunaan lahan dan pertambahan jumlah penduduk. Di Kota Langsa, terdapat tiga kecamatan yang wilayahnya berbatasan dengan wilayah pesisir pantai, yaitu Kecamatan Langsa Timur, Langsa Barat dan Langsa Baroe. Wilayah pesisir pantai di ketiga kecamatan ini merupakan wilayah yang banyak didiami oleh penduduk sehingga dengan tingginya jumlah penduduk didaerah tersebut berpengaruh terhadap tingginya pemanfaatan air tanah dan tidak terarah.

Banyak penduduk yang bertempat tinggal di wilayah pesisir Kota Langsa yang menggunakan sumur bor dengan akuifer dalam sebagai sumber air. Kegiatan pengambilan air tanah secara besarbesaran akan menyebabkan turunnya permukaan air tanah secara drastis. Hal ini terutama berlangsung di daerah pantai yang cenderung menyebabkan terjadinya penyusupan air laut. Eksploitasi air tanah yang dilakukan secara berlebihan (penggunaan sumur bor) khususnya pada daerah berpantai atau pesisir dapat menyebabkan suatu persoalan dimana air laut akan masuk dan terpenetrasi pada daerah pedalaman (Samsuhadi, 2009).

Hasil pengukuran nilai TDS dan DHL yang telah dilakukan, terdapat nilai TDS dan DHL yang berada dibawah baku mutu menurut Keputusan PAHIAA 1986 tentang klasifikasi kualitas air tanah. Klasifikasi tingkat keasinan air tanah peta yang dibuat menggunakan perangkat lunak ArcGIS.

berdasarkan nilai TDS dan DHL di Kota Langsa disajikan pada Tabel 1. Dari Tabel 1 dapat dilihat bahwa berdasarkan klasifikasi tingkat keasinan air tanah di Kota Langsa di kategorikan kedalam tiga kelas yaitu : payau dan agak payau yang ditemui pada masing-masing satu titik sampel $(6,67 \%)$ dan tawar yang ditemui pada tiga belas titik sampel $(86,66 \%)$

Nilai TDS dan DHL dengan klasifikasi kelas keasinan payau terdapat satu titik sampel (Desa Kuala Langsa) yang mempunyai jarak 5,37 km dari pantai. Dari hasil pengukuran juga terdapat beberapa nilai TDS dan DHL sumur yang tidak sesuai dengan teori yang ada, yaitu semakin jauh suatu wilayah maka intrusi yang terjadi akan semakin kecil. Seperti pada titik sampel di Desa Batee Puteh, dimana nilai TDS dan DHL dengan klasifikasi kelas keasinan agak payau meskipun jaraknya $12,21 \mathrm{~km}$ dari pantai. Hal ini dapat diakibatkan oleh letak topografi daerah pengukuran yang dipengaruhi keberadaan Sungai Lueng yang melintasi desa ini yang menjadi jalur masuknya air laut. Selanjutnya wilayah yang mempunyai potensi intrusi air laut pada masa yang akan datang adalah titik sampel di Desa Simpang Wie, Lhok Banie dan Sidodadi apabila tidak dilakukan pengendalian dalam pemanfaatan air tanah.

Menurut Ashriyanti (2011), wilayah intrusi air laut batasnya tidak tetap, berfluktuasi bergantung musim. Pada musim kemarau, sebaran wilayah terintrusi air laut bergeser ke arah selatan semakin menjorok ke arah daratan, sedangkan 
pada musim hujan wilayah terintrusi air laut berkurang ke arah pantai.
Peta zonasi intrusi air laut di Kota Langsa disajikan pada Gambar 3.

Tabel 1. Klasifikasi tingkat keasinan air tanah berdasarkan nilai TDS dan DHL

\begin{tabular}{|c|c|c|c|c|c|c|}
\hline No. & Desa & Kecamatan & $\begin{array}{c}\text { Titik } \\
\text { Koordinat }\end{array}$ & $\begin{array}{c}\text { TDS } \\
(\mathrm{mg} / \mathrm{L})\end{array}$ & $\begin{array}{c}\operatorname{DHL}(\mu \\
\text { mhos/cm) }\end{array}$ & $\begin{array}{c}\text { Klasifikasi } \\
\text { Kelas } \\
\text { Keasinan }\end{array}$ \\
\hline 1 & Seulalah 1 & Langsa Lama & $\begin{array}{l}\text { N 04 } 24^{0} 02,7^{\prime \prime} \\
\text { E 097 } 57^{\prime} 10^{\prime \prime}\end{array}$ & 32 & 72 & Tawar \\
\hline 2 & Seulalah 2 & Langsa Lama & $\begin{array}{l}\text { N } 04^{0} 28^{\prime} 03^{\prime \prime} \\
\text { E } 097^{0} 57^{\prime} 09^{\prime \prime}\end{array}$ & 8 & 21 & Tawar \\
\hline 3 & Lengkong & $\begin{array}{l}\text { Langsa } \\
\text { Baroe }\end{array}$ & $\begin{array}{l}\text { N } 04^{0} 28^{\prime} 16,1^{\prime \prime} \\
\text { E } 097^{0} 56^{\prime} 047^{\prime \prime}\end{array}$ & 2 & 12 & Tawar \\
\hline 4 & Alue Dua & $\begin{array}{l}\text { Langsa } \\
\text { Baroe }\end{array}$ & $\begin{array}{l}\text { N } 04^{0} 30^{\prime} 32,2^{\prime \prime} \\
\text { E } 097^{0} 566^{\prime} 15,9^{\prime \prime}\end{array}$ & 10 & 27 & Tawar \\
\hline 5 & Lhok Banie & Langsa Barat & $\begin{array}{l}\text { N } 04^{0} 29^{\prime} 26,8^{\prime \prime} \\
\text { E } 097^{0} 58^{\prime} 23,6^{\prime \prime}\end{array}$ & 82 & 198 & Tawar \\
\hline 6 & $\begin{array}{l}\text { Kuala } \\
\text { Langsa }\end{array}$ & Langsa Barat & $\begin{array}{l}\text { N } 04^{0} 30 ' 39,3^{\prime \prime} \\
\text { E } 098^{0} 00^{\prime} 37,6^{\prime \prime}\end{array}$ & 3.170 & 3.765 & Payau \\
\hline 7 & Batee Puteh & $\begin{array}{c}\text { Langsa } \\
\text { Timur }\end{array}$ & $\begin{array}{l}\text { N } 04^{0} 27^{\prime} 27,8^{\prime \prime} \\
\text { E } 097^{0} 59^{\prime} 56,5^{\prime \prime}\end{array}$ & 2.512 & 2.682 & $\begin{array}{l}\text { Agak } \\
\text { Payau }\end{array}$ \\
\hline 8 & Sukarejo & $\begin{array}{c}\text { Langsa } \\
\text { Timur }\end{array}$ & $\begin{array}{l}\text { N } 04^{0} 266^{\prime} 59,2^{\prime \prime} \\
\text { E } 098^{0} 01^{\prime} 17,8^{\prime \prime}\end{array}$ & 46 & 114 & Tawar \\
\hline 9 & $\begin{array}{l}\text { Alue } \\
\text { Pineung }\end{array}$ & $\begin{array}{l}\text { Langsa } \\
\text { Timur }\end{array}$ & $\begin{array}{l}\text { N } 04^{0} 266^{\prime} 26,8^{\prime \prime} \\
\text { E } 098^{0} 00^{\prime} 59,6^{\prime \prime}\end{array}$ & 24 & 57 & Tawar \\
\hline 10 & Matang Setui & $\begin{array}{c}\text { Langsa } \\
\text { Timur }\end{array}$ & $\begin{array}{l}\text { N } 04^{0} 26^{\prime} 21^{\prime \prime} \\
\text { E } 098^{0} 00^{\prime} 21,4^{\prime \prime}\end{array}$ & 32 & 72 & Tawar \\
\hline 11 & $\begin{array}{l}\text { Simpang } \\
\text { Wie }\end{array}$ & $\begin{array}{c}\text { Langsa } \\
\text { Timur }\end{array}$ & $\begin{array}{l}\text { N } 04^{0} 266^{\prime} 34^{\prime \prime} \\
\text { E } 097^{0} 59^{\prime} 56,8^{\prime \prime}\end{array}$ & 196 & 405 & Tawar \\
\hline 12 & Bukit Pulo & $\begin{array}{c}\text { Langsa } \\
\text { Timur }\end{array}$ & $\begin{array}{l}\text { N } 04^{0} 26^{\prime} 04,5^{\prime \prime} \\
\text { E } 097^{0} 59^{\prime} 49,2^{\prime \prime}\end{array}$ & 8 & 24 & Tawar \\
\hline 13 & Asam Peutik & $\begin{array}{c}\text { Langsa } \\
\text { Timur }\end{array}$ & $\begin{array}{l}\text { N } 04^{0} 26^{\prime} 33,5^{\prime \prime} \\
\text { E } 097^{0} 59^{\prime} 12,6^{\prime \prime}\end{array}$ & 10 & 27 & Tawar \\
\hline 14 & Sidodadi & Langsa Lama & $\begin{array}{l}\text { N } 04^{0} 27^{\prime} 46,6^{\prime \prime} \\
\text { E } 097^{0} 58^{\prime} 02,4^{\prime \prime}\end{array}$ & 56 & 138 & Tawar \\
\hline 15 & $\begin{array}{l}\text { Tualang } \\
\text { Tengoh }\end{array}$ & Langsa Kota & $\begin{array}{l}\text { N } 04^{0} 28^{\prime} 55,7^{\prime \prime} \\
\text { E } 097^{0} 57^{\prime} 43,4^{\prime \prime}\end{array}$ & 44 & 114 & Tawar \\
\hline
\end{tabular}

Sumber : Data Primer Diolah, 2018.

Berdasarkan peta zona intrusi yang disajikan pada Gambar 3, dapat terlihat bahwa wilayah pesisir Kota Langsa secara umumnya telah terkena intrusi. Beberapa wilayah yang bukan daerah pesisir yang terkena intrusi seperti Desa Batee Puteh diakibatkan oleh keberadaan sungai yang terletak dengan wilayah tersebut. 


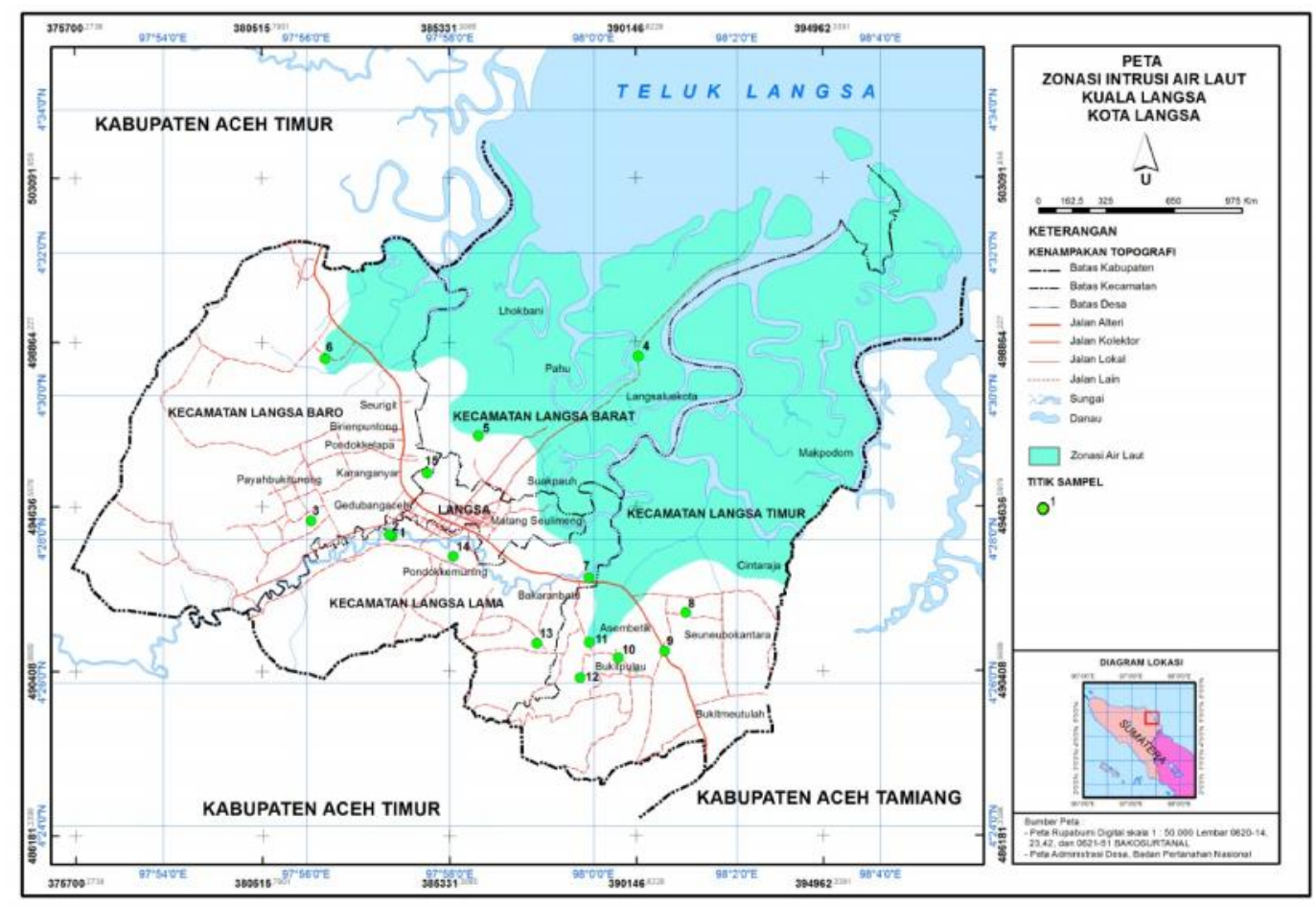

Gambar 3. Zonasi air laut di Kota Langsa

Hasil pengukuran nilai TDS dan DHL yang telah dilakukan, terdapat nilai TDS dan DHL yang secara aktual berada diatas baku mutu menurut Keputusan PAHIAA 1986 tentang klasifikasi kualitas air tanah. Pada wilayah yang dekat dengan garis pantai, nilai TDS dan DHL sangat tinggi, namun ada satu wilayah meskipun terletak jauh dari garis pantai mempunyai nilai TDS dan DHL yang termasuk dalam kategori tingkat keasinan agak payau. Hal ini diduga karena pengaruh dari perubahan tutupan lahan dan juga letak wilayah ini yang dekat dengan sungai sehingga dipengaruhi oleh pasang surut air laut.

Pertambahan penduduk di Kota Langsa telah menyebabkan tingginya eksploitasi air tanah yang dapat menyebabkan intrusi air laut. Intrusi air laut yang terjadi di wilayah pesisir Kota Langsa mempengaruhi masyarakat terutama dalam hal biaya tambahan yang dikeluarkan masyarakat untuk mendapatkan alternatif pengganti sumber air bersih yang digunakan dalam kehidupan sehari-hari. Selama ini mereka membeli air bersih yang bersumber dari Desa Lengkong Kecamatan Langsa Baroe. Air ini dijual secara keliling menggunakan motor viar yang dilengkapi dengan bak untuk menempatkan jerigen yang berisi air dengan harga jual Rp. 3.000/jerigen ukuran 35 liter.

\section{KESIMPULAN}

Zonasi intrusi air laut di Kota Langsa berdasarkan pengukuran nilai TDS dan DHL berada pada klasifikasi tawar sampai payau. Klasifikasi payau dan agak payau yang ditemui pada masing- 
masing satu titik sampel $(6,67 \%)$. Adapun klasifikasi tawar ditemui pada tiga belas titik sampel $(86,66 \%)$.

\section{UCAPAN TERIMAKASIH}

\begin{tabular}{lrr}
\multicolumn{2}{c}{ Ucapan } & terimakasih \\
disampaikan kepada & Rektor \\
Universitas Samudra dan LPPM-PM \\
Universitas Samudra r untuk \\
pembiayaan penelitian ini, melalui \\
Program Dana Hibah Penelitian \\
Dosen Muda di Lingkungan \\
Universitas Samudra Tahun 2018.
\end{tabular}

\section{DAFTAR PUSTAKA}

Ashriyati H. 2011. Kajian Kerentanan pada Wilayah Terintrusi Air Laut di DKI Jakarta. Tesis. FMIPA Magister Ilmu Geografi. Pascasarjana Universitas Indonesia.

Dogan, A., Fares, A. 2008. Effects of Land-Use Changes and Groundwater Pumping on Saltwater Intrusion in Coastal
Watersheds. WIT ransactions on State of the Art in Science and Engineering: 33. WIT Pr.

Effendi, H. 2003. Telaah Kualitas Air Bagi Pengelolaan Sumberdaya dan Lingkungan Perairan. Yogyakarta (ID): Penerbit Kanisius.

Irham, M.N., Achmad, R.T., Widodo, S. 2006 . Pemetaan Sebaran Air Tanah Asin pada Aquifer Dalam di Wilayah Semarang Bawah. Jurnal Fisika. 9(3):137-14.

[PAHIAA-Jakarta] Panitia Ad Hoc Intrusi Air Asin Jakarta. 1986. Klasifikasi Keasinan Perairan Jakarta. Jakarta.

Pla, J.P., Ghiglieri, G., Uras, G. 2014. Seawater Intrusion and Coastal Groundwater Resources Management. Examples from two Mediterranean Regions: Catalonia and Sardinia. Contributions to Science: 10:171-184. ISSN (print): 1575-6343 e-ISSN: 2013$410 X$. 